\title{
Analysis of visual preferences and image features of the floral design in the urban public space
}

\author{
Sung-Eun Yoon", Kyung-Eun Cha \\ Department of floral design, Chungkang College of cultural industries, ICheon, Korea \\ Chun-Ho Park, Eu-Jean Jang \\ College of life sciences \& biotechnology, Korea University, Seoul, Korea
}

\begin{abstract}
In this study, the preferences with regard to floral design in a public space and the correlation between such preferences and the image features of the floral design types were identified. Based on the review of the related literature, the floral designs placed in a public space were classified into three types(the flower bed, container, and three-dimensional sculpture types) according to physical factors, and were classified into two types(the indoor and outdoor types) according to environmental factors. In the floral-design type classified by physical and environmental factors, the flower bed and outdoor types, respectively, were highly preferred.The factor that was found to have the greatest influence on the preference for the flower bed type was 'well-orderedness', which included the adjective categories 'harmonious', 'clean', and 'simple'; that which was found to have the greatest influence on the preference for the outdoor-type floral design was 'identity', which included the adjective categories 'symbolic', 'distinctive', 'harmonious', 'impressive', and 'clean'. It can thus be concluded that the plants that are effectively displayed in a public space can express the nature and identity of the city itself, can be a yardstick for giving value to the city and for evaluating it, and can be important components of the urban landscape. A design that is suitable for the purpose of each public space and that reflects the factors that exert an influence on the users' floral-design type preference should thus be developed.
\end{abstract}

Keywords: Landscape adjectives, Floral-design type, Green city

\section{INTRODUCTION}

About $90 \%$ or more of the whole population of South Korea now live in cities due to the continuous urbanization since the 1960s. As such, the importance of plants that can make the city environment more pleasant is increasing [1]. The pleasantness of a city is now well known to everybody, and 'City Planning Guidelines for Making a Green City' was announced in July 2009 [2]. Urban horticulture can make the life of urbanites pleasant and healthy by curing the urban pathological phenomenon, and can be an important alternative for making a city ecologically sustainable [3]. Urban horticulture in terms of the environment is related with the reduction of greenhouse gases due to polluted environments(e.g., polluted air, fine dust, and noise) and the buildings, roads, concrete, and asphalt, and with the resulting aesthetic environment [4].

Indoor and outdoor floral design using plants, which are part of urban horticulture, is considered an important method to secure the greenbelt of a city and to enhance the qualitative image of the urban landscape [5]-[7]. The current trend involves the use of plants and various objects for floral design.

\footnotetext{
*Corresponding author. E-mail : yseyse0@hanmail.net

Manuscript received Sep. 14, 2010 ; accepted Oct. 25, 2010
}

Moreover, floral design has become a field of spatial presentation and has boundless potentials for urban spaces [7]. Given that the purpose of floral design in a city is to enhance the public environment, it is important for the floral design in an urban public space to reflect the liking and preferences of the residents and users of the public space [7]. Most of the floral designs displayed in urban spaces are created based on subjective planning; they thus do not always elicit sympathy from the users and do not always satisfy them [8]. Moreover, most of the previous studies on floral design for urban spaces were based on the subjective presentation of concepts and works. Objective studies on the visual influence felt by the users(the objects), or studies that aim to find the objective aesthetic response to public spaces, are rare [9]. Thus, the purpose of this study was to analyze the visual-image features of the floral design in the public space of a city and the preferences by floral-design type to enhance the satisfaction of the users by improving their visual preferences and by making floral design perform an ecological function in public spaces. It is hoped that this study will contribute to the establishment of a logical urban-afforestation design by developing a design and selecting plants that can enhance the satisfaction of urbanites, and by providing basic data for the use of such floral designs. 


\section{MATERIALS AND METHODS}

\subsection{Materials}

A survey was conducted among the residents of the province of Kyunggido on the whole and Seoul City in particular to identify the correlation between the image features by type of floral designs placed in the public spaces in Kyunggido and Seoul, respectively, on one hand, and the residents' preferences on the other. Based on the review of the related literature, the floral designs placed in a public space were classified into three types(the flower bed, container, and three-dimensional sculpture types) according to physical factors(Fig. 1) [9], and were classified into two types(the indoor and outdoor types) according to environmental factors [10].

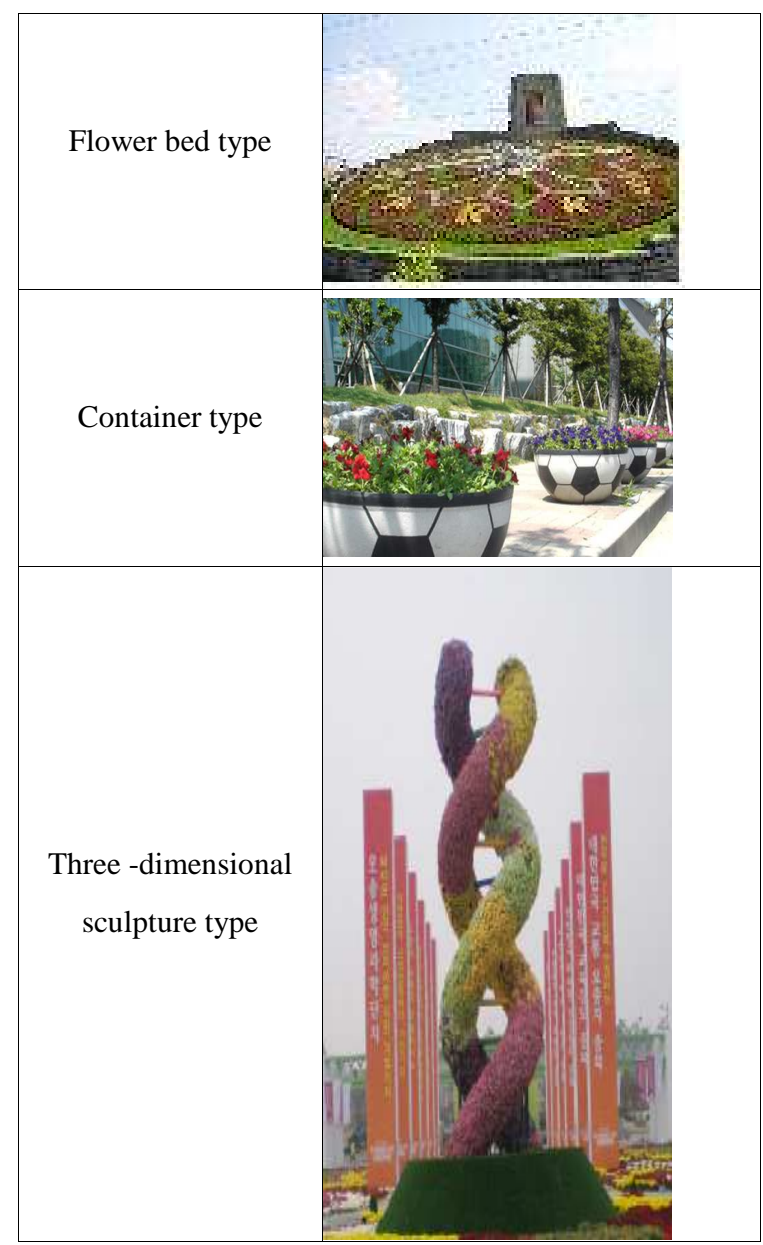

Fig. 1. Floral design types according to physical factors

\subsection{Selection of categories to be investigated}

The categories to be investigated included the preferences by type of floral-design display, the image features described by adjectives for a landscape, and general items, all of which were based on the related literature [6],[8],[9],[11]-[12]. For the evaluation categories, the applicable yardstick words used in the previous studies were first selected through literature review [5],[9],[12],[13]-[14], and a preliminary investigation was performed to test the reliability and validity of the words based on the result of the reliability test. A total of 20 validated adjectives were selected. A list of antonym adjectives was presented to the subjects using the semantic differential scale described by Osgood [13]. Each set of antonym adjectives was divided into a 5-point Likert scale, and the subjects were asked to mark the word that they felt was most appropriate [16]. Based on the measurement values, the image features were quantified.

\subsection{Methods and sample number}

The survey was conducted 30 times, from July 1 to 30, 2010. A total of 400 sets of survey questionnaires were distributed, and 346 sets of accomplished questionnaires were used for the analysis, excluding the 31 unreturned sets and the 23 sets that were incompletely or inappropriately filled out.

\subsection{General characteristics of the respondents}

Of the total of 346 respondents, 133 were male(38.4\%) and 213 were female $(61.6 \%)$. The proportion of the respondents in their $40 \mathrm{~s}$ was the highest $(42.5 \%)$, followed by those in their $30 \mathrm{~s}$ $(32.4 \%)$. The number of office workers was the largest $(139$; $40.2 \%)$, followed by students(18.8\%) and housewives(16.2\%). The proportion of the respondents who reside in Seoul was $53.8 \%$, followed by those residing in Kyunggido(46.2\%) (Table 1).

Table 1. General characteristics of the subjects

\begin{tabular}{|c|c|c|c|c|}
\hline Variable & Content & $\mathbf{N}$ & $\%$ & $\mathbf{P}\left(\chi^{2}\right)$ \\
\hline \multirow{2}{*}{ Gender } & Male & 133 & 38.4 & \multirow{2}{*}{$\begin{array}{c}0.000 \\
(18.497)\end{array}$} \\
\hline & Female & 213 & 61.6 & \\
\hline \multirow{4}{*}{ Age } & $20 \mathrm{~s}$ & 35 & 10.1 & \multirow{4}{*}{$\begin{array}{c}0.000 \\
(201.428)\end{array}$} \\
\hline & $30 \mathrm{~s}$ & 112 & 32.4 & \\
\hline & $40 \mathrm{~s}$ & 147 & 42.5 & \\
\hline & 50s and over & 52 & 15.0 & \\
\hline \multirow{2}{*}{$\begin{array}{c}\text { Academic } \\
\text { background }\end{array}$} & Above college & 194 & 55.0 & \multirow{2}{*}{$\begin{array}{c}0.041 \\
(4.173)\end{array}$} \\
\hline & Below college & 154 & 44.5 & \\
\hline \multirow{8}{*}{ Job } & Office worker & 139 & 40.2 & \multirow{8}{*}{$\begin{array}{c}0.000 \\
(301.786)\end{array}$} \\
\hline & Student & 65 & 18.8 & \\
\hline & Housewife & 56 & 16.2 & \\
\hline & $\begin{array}{l}\text { Service } \\
\text { industry }\end{array}$ & 23 & 6.6 & \\
\hline & Professional & 23 & 6.6 & \\
\hline & Self-employed & 19 & 5.5 & \\
\hline & Public servant & 4 & 1.2 & \\
\hline & Miscellaneous & 17 & 4,9 & \\
\hline \multirow{2}{*}{ Residence } & Seoul & 186 & 53.8 & \multirow{2}{*}{$\begin{array}{l}0.0401 \\
(8.533)\end{array}$} \\
\hline & Kyunggido & 160 & 46.2 & \\
\hline
\end{tabular}

\subsection{Analysis method used}

The data that were collected in this study were analyzed using SPSS/WIN(version 12.0). Descriptive statistic analysis 
was performed to identify the preferences and awareness by display type. To identify the image features by display type, measurement was done using 20 sets of adjectives, each set having a 5-point Likert scale. The analysis was based on the median value because the average value was not sufficient for making a determination. First, to analyze the image features that exert an influence on the preference by display type, factor analysis was performed for the investigation categories of the total of 20 sets that were used for each display type. For factor analysis, principal-components analysis was used. Varimax rotation was used for factor rotation, and the factors were selected based on the eigenvalue of 1 or above. The reliability of these factors was tested by calculating Cronbach's value. Correlation analysis was performed to ascertain the level of correlation between the factors summarized by factor analysis on one hand and preference on the other. Regression analysis was performed to identify the factors that influence the preference using the factors that have significant correlations $(\mathrm{p}<0.05)$.All equations must be typed or written neatly in black. They should be numbered consecutively throughout the text. Equation numbers should be enclosed in parentheses and flushed right. Equations should be referred to as Eq. $(\mathrm{X})$ in the text where $\mathrm{X}$ is the equation number. In multiple-line equations, the number should be given on the last line.

\section{RESULTS AND DISCUSSION}

\subsection{All Analysis of preference by display type}

To identify the users' preferences with regard to the floral design in a public space by display type, frequency analysis was performed using the measurement values obtained from the survey questionnaire based on a 5-point Likert scale. For the display types classified based on physical factors, the respondents showed the highest preference for the flower bed type(3.39), followed by the container type(2.99) and the threedimensional sculpture type (2.73); and for the types of floral design classified based on environmental factors, the respondents showed a preference for the outdoor type(3.52) over the indoor type(2.91) (Table 2). The preference for the outdoor type over the indoor type is considered attributable to the respondents' familiarity with the flower bed formed along the roadside [8].

Table 2. Analysis of the floral-design type preference

\begin{tabular}{|c|c|c|c|c|c|c|c|c|c|}
\hline \multicolumn{2}{|r|}{ Factor } & $\begin{array}{c}1 \\
(\%)\end{array}$ & $\begin{array}{c}2 \\
(\%)\end{array}$ & $\begin{array}{c}3 \\
(\%)\end{array}$ & $\begin{array}{c}4 \\
(\%)\end{array}$ & $\begin{array}{c}5 \\
(\%)\end{array}$ & Mean & Median & $\underset{\text { error }}{\text { Std }}$ \\
\hline \multirow{3}{*}{ Physical } & Flower bed type & 1.2 & 9.8 & 45.7 & 35.5 & 7.8 & 3.39 & 3.00 & 0.81 \\
\hline & Container type & 2.6 & 22.5 & 52.6 & 18.2 & 4.0 & 2.99 & 3.00 & 0.82 \\
\hline & Three -dimensional sculpture type & 6.9 & 32.9 & 41.3 & 17.6 & 1.2 & 2.73 & 3.00 & 0.87 \\
\hline \multirow{2}{*}{ Environmental } & Indoor type & 2.6 & 34.1 & 37.3 & 21.7 & 4.3 & 2.91 & 3.00 & 0.91 \\
\hline & Outdoor type & 0.0 & 13.0 & 34.4 & 39.9 & 12.7 & 3.52 & 4.00 & 0.88 \\
\hline
\end{tabular}

1=Strongly dislike; 2=Dislike; 3=Like a little; 4=Like; 5=Like very much

\subsection{Analysis of the floral-design image displayed at a public space}

To identify the image features of the floral design in a public space, analysis was performed using 20 sets of adjectives and a 5-point Likert scale. In the types classified by physical factor, for the flower bed type, the respondents chose adjectives such as 'refreshing', 'indistinctive', 'nonsymbolic', 'inelegant', and 'natural' to describe the features of the image; for the container type, 'indistinctive', 'nonsymbolic', 'simple', 'unimpressive', 'heavy', and 'hard'; and for the three-dimensional sculpture type, 'dynamic', 'dirty', 'confusing', 'heavy', and 'hard'(Table $3)$. In the types classified by environmental factor, for the indoor type, the respondents chose 'nonsymbolic' and 'unimpressive'; and for the outdoor type, 'refreshing', 'inelegant', and 'natural'(Table 3). The results of the analysis showed that overall, the adjectives 'indistinctive', 'nonsymbolic', and 'unimpressive' were most often chosen, indicating that the present floral design in the public space does not make a favorable impression on the users, consistent with the results of the study conducted by Kim [9]. It is considered that to increase the users' preference, the floral design should be formed based on the preferred factors, according to the environment of the place. Adjectives such as 'natural' and 'refreshing' indicated that the floral design acted as a landscape factor that makes the artificial urban environment pleasant, and that the respondents had positive images of the floral design(Table 3). In contrast, adjectives such as 'beautiful', 'clean', and 'harmonious' were chosen relatively less often, indicating that the users' satisfaction was low due to the poor management of the floral ornaments at the public space [17] and the lack of harmony with the other environmental factors in the place [10].

Table 3. Analysis of the floral-design image displayed at public spaces

\begin{tabular}{|c|c|c|c|c|c|}
\hline Evaluation words & Flower bed type & Container type & $\begin{array}{c}\text { Three-dimensional } \\
\text { sculpture type }\end{array}$ & Indoor type & Outdoor type \\
\hline
\end{tabular}




\begin{tabular}{|c|c|c|c|c|c|c|c|c|c|c|c|c|c|c|c|}
\hline & $\stackrel{\Xi}{\tilde{E}}$ & 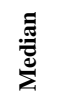 & क & 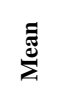 & 芯 & 矛 & 氖 & & 离 & Е & 氖 & $\vec{\varpi}$ & Е & 䒿 & $\bar{b}$ \\
\hline Unrefreshing-refreshing & 3.68 & 4.00 & 0.84 & 3.10 & 3.00 & 0.68 & 3.13 & 3.00 & 0.82 & 3.30 & 3.00 & 0.86 & 3.82 & 4.00 & 0.76 \\
\hline Ugly-beautiful & 3.23 & 3.00 & 0.76 & 3.21 & 3.00 & 0.63 & 2.95 & 3.00 & 0.93 & 3.35 & 3.00 & 0.70 & 3.07 & 3.00 & 0.89 \\
\hline $\begin{array}{l}\text { Uncomfortable- } \\
\text { comfortable }\end{array}$ & 3.29 & 3.00 & 0.87 & 2.97 & 3.00 & 1.01 & 3.13 & 3.00 & 1.07 & 3.42 & 3.00 & 0.87 & 3.30 & 3.00 & 0.87 \\
\hline Dull-dynamic & 2.95 & 3.00 & 0.84 & 2.74 & 3.00 & 0.83 & 3.51 & 4.00 & 0.96 & 3.16 & 3.00 & 0.86 & 3.24 & 3.00 & 0.84 \\
\hline Dirty-clean & 2.90 & 3.00 & 0.95 & 2.94 & 3.00 & 0.96 & 2.36 & 2.00 & 0.94 & 2.88 & 3.00 & 0.94 & 2.62 & 3.00 & 0.92 \\
\hline Indistinctive-distinctive & 2.40 & 2.00 & 0.78 & 2.21 & 2.00 & 0.93 & 3.24 & 3.00 & 0.99 & 2.47 & 3.00 & 0.91 & 2.67 & 3.00 & 1.03 \\
\hline Nonsymbolic-symbolic & 2.54 & 2.00 & 0.83 & 2.12 & 2.00 & 0.85 & 2.96 & 3.00 & 1.14 & 2.13 & 2.00 & 1.02 & 2.73 & 3.00 & 0.95 \\
\hline Complex-simple & 2.95 & 3.00 & 1.00 & 3.58 & 4.00 & 0.95 & 2.85 & 3.00 & 1.00 & 3.33 & 3.00 & 0.70 & 3.18 & 3.00 & 0.82 \\
\hline Inharmonious-harmonious & 2.97 & 3.00 & 0.96 & 2.74 & 3.00 & 0.94 & 2.57 & 3.00 & 0.87 & 3.02 & 3.00 & 0.85 & 3.26 & 3.00 & 1.03 \\
\hline Unimpressive-impressive & 2.60 & 3.00 & 0.81 & 2.58 & 2.00 & 1.06 & 3.10 & 3.00 & 1.07 & 2.38 & 2.00 & 1.02 & 2.85 & 3.00 & 0.96 \\
\hline Bustling-calm & 2.99 & 3.00 & 0.66 & 3.16 & 3.00 & 0.93 & 2.38 & 2.00 & 0.80 & 2.99 & 3.00 & 0.78 & 2.76 & 3.00 & 0.91 \\
\hline Not fresh-fresh & 2.97 & 3.00 & 0.84 & 2.97 & 3.00 & 0.90 & 2.65 & 3.00 & 0.84 & 2.75 & 3.00 & 0.79 & 3.18 & 3.00 & 1.19 \\
\hline Inelegant-elegant & 2.41 & 2.00 & 0.89 & 2.79 & 3.00 & 0.93 & 2.45 & 2.00 & 0.80 & 2.77 & 3.00 & 0.98 & 2.23 & 2.00 & 0.93 \\
\hline Artificial-natural & 3.82 & 4.00 & 0.98 & 2.93 & 3.00 & 0.80 & 2.93 & 3.00 & 1.01 & 3.10 & 3.00 & 0.83 & 4.16 & 4.00 & 0.63 \\
\hline Heavy-light & 3.00 & 3.00 & 0.82 & 2.11 & 2.00 & 0.81 & 2.01 & 2.00 & 0.85 & 2.58 & 3.00 & 0.97 & 2.73 & 3.00 & 0.90 \\
\hline Small-enormous & 2.60 & 3.00 & 0.87 & 2.93 & 3.00 & 0.85 & 3.34 & 3.00 & 1.14 & 2.73 & 3.00 & 0.89 & 3.14 & 3.00 & 0.86 \\
\hline Unfamiliar-familiar & 3.12 & 3.00 & 0.92 & 3.40 & 3.00 & 0.77 & 2.75 & 3.00 & 0.82 & 3.39 & 3.00 & 0.91 & 3.21 & 3.00 & 0.83 \\
\hline New-old & 3.11 & 3.00 & 0.90 & 2.93 & 3.00 & 0.78 & 2.79 & 3.00 & 0.74 & 3.33 & 3.00 & 0.82 & 3.11 & 3.00 & 0.65 \\
\hline Unstylish-stylish & 2.72 & 3.00 & 1.10 & 2.66 & 3.00 & 0.97 & 2.90 & 3.00 & 0.99 & 2.61 & 3.00 & 0.81 & 2.77 & 3.00 & 0.99 \\
\hline Hard-soft & 3.40 & 3.00 & 0.81 & 1.71 & 2.00 & 0.71 & 2.08 & 2.00 & 0.88 & 2.56 & 3.00 & 1.04 & 2.80 & 3.00 & 0.80 \\
\hline
\end{tabular}

3.3. Analysis of the floral-design image factors in a public space and of the correlation between such factors and the display type preference

The floral-design image factors in a public space, and their relation with preference, were analyzed. In the display types classified by physical factor, the flower bed type was analyzed using nine image factors. To identify the psychological factors related with the preference for the flower bed type, correlation analysis was performed. Factors $1(0.266)$ and 2(0.124) were found to have positive correlations with the preference for the flower bed type, and factor 4(-0.141) a negative
correlation(Table 4). The comparison of the standardizedcoefficient beta values showed that 'factor 1 ' $(0.266)$ had the greatest influence on the preference for the flower bed type, followed by factor 2(0.124) (Table 5). 'Factor 1' included the adjective categories 'harmonious', 'clean', and 'simple'. These categories can be regarded as 'well-orderedness' reflecting harmony, comfort, and orderedness[14]. This indicates that the users prefer clean, organized spaces. Thus, when designing a flower bed, the shape of the bed and the plants should be simple, clean, and well maintained by considering wellorderedness.

Table 4. Analysis of the image factors of the flower bed type classified by physical factor

\begin{tabular}{|c|c|c|c|c|c|c|}
\hline Factor & Adjectives & $\begin{array}{l}\text { Eigen } \\
\text { value }\end{array}$ & $\begin{array}{c}\text { Accumulated } \\
\text { dispersion }\end{array}$ & $\begin{array}{c}\text { Correlation } \\
\text { coefficient }\end{array}$ & p & Cronbach's $\alpha$ \\
\hline Factor 1 & Harmonious, clean, simple & 2.194 & 10.970 & $0.266^{*}$ & $0.000 * *$ & \multirow{9}{*}{0.552} \\
\hline Factor 2 & Elegant, soft, fresh & 1.438 & 18.159 & $0.124 *$ & $0.021 *$ & \\
\hline Factor 3 & Light, enormous & 1.365 & 24.986 & -0.070 & 0.192 & \\
\hline Factor 4 & Impressive, unstylish & 1.363 & 31.803 & $-0.141 *$ & $0.009 * *$ & \\
\hline Factor 5 & Fresh, dull, natural & 1.293 & 38.266 & 0.091 & 0.093 & \\
\hline Factor 6 & Old, distinctive, familiar & 1.262 & 44.575 & 0.074 & 0.167 & \\
\hline Factor 7 & Symbolic, beautiful & 1.255 & 50.851 & 0.042 & 0.433 & \\
\hline Factor 8 & Calm & 1.250 & 57.103 & 0.050 & 0.359 & \\
\hline Factor 9 & Comfortable & 1.097 & 62.585 & 0.060 & 0.266 & \\
\hline
\end{tabular}

The correlation coefficient is significant at the 0.01 level. 
Table 5. Regression analysis coefficient for the correlation between the flower bed type image classified by physical factor and preference

\begin{tabular}{|c|c|c|c|c|c|}
\hline \multirow{2}{*}{ Model } & \multicolumn{2}{|c|}{ Non-standardized coefficient } & Standardized coefficient & \multirow{2}{*}{ t } & \multirow{2}{*}{ Significance probability } \\
\cline { 2 - 5 } & B & Std error & Beta & 76.886 & 0.000 \\
\hline (Constant) & 3.474 & 0.045 & & 5.211 & 0.000 \\
Factor 1 & 0.236 & 0.045 & 0.266 & 2.423 & 0.016 \\
Factor 2 & 0.110 & 0.045 & 0.124 & -2.754 & 0.006 \\
Factor 4 & -0.125 & 0.045 & -0.141 & \\
\hline
\end{tabular}

The container type was analyzed using a total of seven image factors. The container type was found to have a positive correlation with preference $(\mathrm{p}=0.150)$. Factors $2(\mathrm{p}=0.568)$, $3(\mathrm{p}=0.284), \quad 4(\mathrm{p}=0.692), \quad 5(\mathrm{p}=0.148), \quad 6(\mathrm{p}=0.349), \quad$ and $7(\mathrm{p}=0.964)$ were found to have insignificant correlations with the preference for the container type ( $p>0.05$ ) (Table 6 and 7). 'Factor 1', which was found to have the greatest influence on the preference for the aforementioned floral-design type, included the adjective categories 'distinctive', 'harmonious', 'stylish', and 'clean', all of which reflect 'harmony' [14]. It is thus believed that the users prefer container types that are presented in such a way as to provide visual beauty through harmony with the surrounding environment. As the containertype floral designs can be freely arranged due to its movability, the container itself has a structural meaning; the container and plants, which change during the four seasons, have harmony among them, thus providing a refreshing environment, and they consist of individual containers, allowing easy maintenance and management [18]. The container-type floral design is thus considered effective for urban spaces.

Table 6. Analysis of the container type image classified by physical factor

\begin{tabular}{|c|c|c|c|c|c|c|}
\hline Factor & Adjectives & $\begin{array}{l}\text { Eigen } \\
\text { value }\end{array}$ & $\begin{array}{c}\text { Accumulated } \\
\text { dispersion }\end{array}$ & $\begin{array}{l}\text { Correlation } \\
\text { coefficient }\end{array}$ & $\mathbf{p}$ & Cronbach's $\alpha$ \\
\hline Factor 1 & $\begin{array}{l}\text { Distinctive, harmonious, } \\
\text { stylish, clean }\end{array}$ & 1.903 & 9.515 & $0.150 *$ & $0.005 * *$ & \multirow{7}{*}{0.554} \\
\hline Factor 2 & Symbolic, fresh, ugly & 1.515 & 17.091 & 0.031 & 0.568 & \\
\hline Factor 3 & Simple, calm & 1.490 & 24.542 & 0.058 & 0.284 & \\
\hline Factor 4 & $\begin{array}{l}\text { Small, fresh, impressive, } \\
\text { elegant }\end{array}$ & 1.487 & 31.977 & -0.021 & 0.692 & \\
\hline Factor 5 & Natural, familiar, heavy & 1.472 & 39.337 & 0.078 & 0.148 & \\
\hline Factor 6 & Comfortable, soft & 1.408 & 46.379 & 0.051 & 0.349 & \\
\hline Factor 7 & Simple, artificial & 1.361 & 53.186 & 0.002 & 0.964 & \\
\hline
\end{tabular}

The correlation coefficient is significant at the 0.01 level.

Table 7. Regression analysis coefficient for the correlation between the container type image classified by physical factor and preference

\begin{tabular}{|c|c|c|c|c|c|}
\hline \multirow{2}{*}{ Model } & \multicolumn{2}{|c|}{ Non-standardized coefficient } & Standardized coefficient & \multirow{2}{*}{ t } & Significance probability \\
\cline { 2 - 5 } & B & Std error & Beta & 73.736 & 0.000 \\
\hline (Constant) & 3.474 & 0.047 & & 2.811 & 0.005 \\
\hline
\end{tabular}

The three-dimensional sculpture type was analyzed using a total of nine image factors. Factors 2(0.178), 3(0.142), and 4(0.196) were found to have positive correlations with the preference for the three-dimensional sculpture type while factors $1(\mathrm{p}=0.197), 5(\mathrm{p}=0.155), 6 \quad(\mathrm{p}=0.085), \quad 7(\mathrm{p}=0.478)$, $8(\mathrm{p}=0.454)$, and $9(\mathrm{p}=0.143)$ were found to have insignificant correlations with the same $(\mathrm{p}>0.05)$ (Table 8$)$. The comparison of the standardized-coefficient beta values showed that 'factor 4'(0.196), which included the adjective categories 'distinctive', 'ugly', and 'impressive', all of which can be regarded as 'aesthetic features', had the greatest influence on the preference for the three-dimensional sculpture type, followed by factors 2
(0.178) and 3(0.142) (Table 9). It is thus considered that the design of the container should be improved to enhance the structural beauty compared with other floral-design types. Meanwhile, it is believed that the inharmony of the floral designs presented in a three-dimensional sculpture with the surrounding environment, and poor management, exert an adverse influence on the preference for the aforementioned floral-design type. Thus, floral design in the form of a threedimensional sculpture should be done with thorough consideration and analysis of the surrounding environment because such floral design sculptures are environmental components of the urban environment. 
Table 8. Analysis of the three-dimensional sculpture type image factor classified by physical factor

\begin{tabular}{|c|c|c|c|c|c|c|}
\hline Factor & Adjectives & $\begin{array}{l}\text { Eigen } \\
\text { value }\end{array}$ & $\begin{array}{l}\text { Accumulate } \\
\text { d dispersion }\end{array}$ & $\begin{array}{c}\text { Correlation } \\
\text { coefficient }\end{array}$ & $\mathbf{p}$ & Cronbach's $\alpha$ \\
\hline Factor 1 & Soft, unfamiliar & 1.727 & 8.635 & 0.070 & 0.197 & \multirow{9}{*}{0.585} \\
\hline Factor 2 & $\begin{array}{l}\text { Comfortable, artificial, calm, } \\
\text { unpleasant }\end{array}$ & 1.704 & 17.154 & $0.178^{*}$ & $0.001 * *$ & \\
\hline Factor 3 & Harmonious, symbolic & 1.499 & 24.648 & $0.142 *$ & $0.008 * *$ & \\
\hline Factor 4 & Distinctive, ugly, impressive & 1.451 & 31.901 & $0.196 *$ & $0.000 * *$ & \\
\hline Factor 5 & Fresh, simple, heavy & 1.391 & 38.858 & -0.77 & 0.155 & \\
\hline Factor 6 & Stylish, clean & 1.364 & 45.678 & 0.093 & 0.085 & \\
\hline Factor 7 & Elegant & 1.308 & 52.218 & -0.038 & 0.478 & \\
\hline Factor 8 & Dynamic & 1.288 & 58.657 & 0.040 & 0.454 & \\
\hline Factor 9 & Enormous, new & 1.249 & 64.903 & 0.079 & 0.143 & \\
\hline
\end{tabular}

The correlation coefficient is significant at the 0.01 level.

Table 9. Regression analysis coefficient for the correlation between the three-dimensional sculpture type image classified by physical factor and preference

\begin{tabular}{|c|c|c|c|c|c|}
\hline \multirow{2}{*}{ Model } & \multicolumn{2}{|c|}{ Non-standardized coefficient } & \multirow{2}{*}{$\begin{array}{c}\text { Standardized coefficient } \\
\text { Beta }\end{array}$} & \multirow{2}{*}{$\mathbf{t}$} & \multirow{2}{*}{ Significance probability } \\
\hline & $\mathbf{B}$ & Std error & & & \\
\hline (Constant) & 3.474 & 0.046 & & 76.227 & 0.000 \\
\hline Factor 2 & 0.158 & 0.046 & 0.178 & 3.461 & 0.001 \\
\hline Factor 3 & 0.126 & 0.046 & 0.142 & 2.755 & 0.006 \\
\hline Factor 4 & 0.174 & 0.046 & 0.196 & 3.808 & 0.000 \\
\hline
\end{tabular}

To analyze the difference in image features due to the difference in environmental space, an investigation was made of indoor and outdoor floral design. The indoor type was analyzed using a total of nine image factors. Factors $1(0.126)$, $3(0.110)$, and 4(0.158) were found to have positive correlations with the preference for the indoor type(Table 10). The comparison of the standardized-coefficient beta values showed that 'factor 4'(0.158) which included the adjective categories 'elegant' and 'distinctive', both of which can be regarded as 'distinction', had the greatest influence on the preference for the indoor type (Table 11).

Table 10. Analysis of the correlation between the indoor type image factor classified by environmental factor

\begin{tabular}{|c|c|c|c|c|c|c|}
\hline Factor & Adjectives & $\begin{array}{l}\text { Eigen } \\
\text { value }\end{array}$ & $\begin{array}{l}\text { Accumulated } \\
\text { dispersion }\end{array}$ & $\begin{array}{c}\text { Correlation } \\
\text { coefficient }\end{array}$ & $\mathbf{p}$ & Cronbach's $\alpha$ \\
\hline Factor 1 & Small, light, impressive & 1.747 & 8.737 & $0.126^{*}$ & $0.019 *$ & \multirow{9}{*}{0.542} \\
\hline Factor 2 & Beautiful, familiar, simple & 1.736 & 17.417 & 0.073 & 0.174 & \\
\hline Factor 3 & Fresh, symbolic, new & 1.600 & 25.415 & $0.110 *$ & 0.040 & \\
\hline Factor 4 & Elegant, distinctive & 1.563 & 33.228 & $0.158 *$ & $0.003 * *$ & \\
\hline Factor 5 & Dynamic, inharmonious & 1.452 & 40.489 & 0.053 & 0.321 & \\
\hline Factor 6 & Stylish, soft & 1.370 & 47.340 & 0.036 & 0.505 & \\
\hline Factor 7 & Calm, fresh & 1.324 & 53.962 & 0.030 & 0.577 & \\
\hline Factor 8 & Natural, clean & 1.268 & 60.300 & 0.009 & 0.871 & \\
\hline Factor 9 & Comfortable & 1.180 & 66.200 & -0.049 & 0.359 & \\
\hline
\end{tabular}

The correlation coefficient is significant at the 0.01 level.

Table 11. Regression analysis coefficient for the correlation between the indoor type image classified by environmental factor and preference

\begin{tabular}{|l|c|c|c|c|} 
Model & Non-standardized coefficient & Standardized coefficient & $\mathbf{t}$ & Significance probability \\
\hline
\end{tabular}




\begin{tabular}{|c|c|c|c|c|c|}
\hline & B & Std error & Beta & & \\
\hline (Constant) & 3.474 & 0.047 & & 74.696 & 0.000 \\
Factor 4 & 0.140 & 0.047 & 0.158 & 3.003 & 0.003 \\
Factor 1 & 0.111 & 0.047 & 0.126 & 2.388 & 0.017 \\
Factor 3 & 0.098 & 0.047 & 0.110 & 2.096 & 0.037 \\
\hline
\end{tabular}

The outdoor type was analyzed using a total of eight image factors. Factors $1(0.268)$ and $2(0.113)$ were found to have positive correlations with the preference for the outdoor type, factor $4(-0.154)$ a negative correlation, and factors $3(\mathrm{p}=0.682)$, $5(\mathrm{p}=0.160), \quad 6(\mathrm{p}=0.205), \quad 7(\mathrm{p}=0.934), \quad$ and $\quad 8(\mathrm{p}=0.250)$ insignificant correlations $(\mathrm{p}>0.05)$ (Table 12). The comparison of the standardized-coefficient beta values showed that factor $1(0.268)$, which included the adjective categories 'symbolic', 'distinctive', 'harmonious', 'impressive', and 'clean', all of which reflect 'identity', had the greatest influence on the preference for the outdoor type(Table 13). It is thus believed that the plants that are effectively displayed at a public outdoor space in a city can play an important role in expressing the nature and identity of the city, can be a yardstick for giving value to the city and for evaluating it, and can be important components of the urban landscape.

Table 12. Analysis of the outdoor type image factor classified by environmental factor

\begin{tabular}{|c|c|c|c|c|c|c|}
\hline Factor & Adjectives & $\begin{array}{l}\text { Eigen } \\
\text { value }\end{array}$ & $\begin{array}{c}\text { Accumulated } \\
\text { dispersion }\end{array}$ & $\begin{array}{c}\text { Correlation } \\
\text { coefficient }\end{array}$ & $\mathbf{p}$ & Cronbach's $\alpha$ \\
\hline Factor 1 & $\begin{array}{l}\text { Symbolic, distinctive, } \\
\text { harmonious, } \\
\text { impressive, clean }\end{array}$ & 1.936 & 9.679 & $0.268^{*}$ & $0.000 * *$ & \\
\hline Factor 2 & Stylish, fresh & 1.546 & 17.411 & $0.113^{*}$ & $0.036^{*}$ & \\
\hline Factor 3 & Natural, old, inelegant & 1.522 & 25.020 & 0.022 & 0.682 & \\
\hline Factor 4 & Familiar & 1.519 & 32.613 & $-0.154^{*}$ & $0.004 * *$ & 0.554 \\
\hline Factor 5 & $\begin{array}{l}\text { Simple, beautiful, } \\
\text { dynamic }\end{array}$ & 1.515 & 40.187 & 0.076 & 0.160 & \\
\hline Factor 6 & Calm, light, unpleasant & 1.431 & 47.341 & -0.068 & 0.205 & \\
\hline Factor 7 & Comfortable & 1.420 & 54.443 & 0.004 & 0.934 & \\
\hline Factor 8 & Hard, enormous & 1.404 & 61.461 & 0.062 & 0.250 & \\
\hline
\end{tabular}

The correlation coefficient is significant at the 0.01 level.

Table 13. Regression analysis coefficient for the correlation between the image of the outdoor type classified by environmental factor and preference

\begin{tabular}{|c|c|c|c|c|c|}
\hline \multirow{2}{*}{ Model } & Non-standardized coefficient & Standardized coefficient & \multirow{2}{*}{$\begin{array}{c}\text { Significance } \\
\text { probability }\end{array}$} \\
\cline { 2 - 5 } & B & Std error & Beta & 76.976 & 0.000 \\
Factor 1 & 3.474 & 0.045 & & 5.249 & 0.000 \\
Factor 4 & 0.237 & 0.045 & 0.268 & -3.015 & 0.003 \\
Factor 2 & -0.136 & 0.045 & -0.154 & 2.204 & 0.028 \\
\hline
\end{tabular}

Based on the overall study results, first, it is considered that floral design's functional role of improving pleasantness and its aesthetic role of making the urban landscape beautiful should be reinforced to enhance the urbanites' preferences with regard to and satisfaction with floral design. Second, to do so, floral design in a public space should be done in such a way as to achieve a balance with the surrounding environment by analyzing the relevant space. Finally, a design that reflects the factors identified in this study that exert an influence on the users' design type preferences should be developed for floral design in a public space. Further studies that classify indoor and outdoor floral design in greater detail, and more systematic investigations, are needed. In addition, extensive studies are required to identify the suitable plant types for each design type, and the effective design method, by conducting a survey among and interviews of the floral-design experts in the field, such as on horticulture, environmental design, and floral design.

\section{ACKNOWLEDGEMENT}

This work was supported by the National Research Foundation of Korea Grant funded by the Korean Government (NRF-2010332-G00038)

\section{REFERENCES}

[1] Y.-S. Moon, J.-A. Lee, J.-h. Chon, and H.-J. Park, "Economic Valuation of an Urban Landscape: With a Focus on Independence Park", Journal of the Korean Institute of Landscape Architecture, vol. 37, no. 2, Mar. 
2009, pp.70-77.

[2] S.-C. Park, and J.-Y. Kim, "Urban Planning Measurements in Pursuit of a Low-carbon Green City Case Analyses of Basic Planning Elements and Spatial Urban Structures in Korea and Japan", Journal of the Korean Regional Development Association, vol. 22, no. 1, Mar. 2010, pp.17- 51.

[3] D.-H. Jang, and S.-Y. Soh, "A Study on Management of Urban Agriculture: The Case of Agriculture in Seoul", Bulletin of the Agricultural College, vol. 36, Sep. 2005, pp.86-102.

[4] W. Mun, B.-R. Jung, K.-S. Kim, Y.-K. Joo, J.-S. Lee, B.C. Choi, S.-D. Lee, J.-S. Song, M.-H. Suh, Y.-B. Lee, K.-J. Kim, K.C. Son, and H.K. Hong, A Story of Hoticulture in Life, Korea Broadcasting University Press, Seoul, 2008.

[5] Y. Ken, Designing with Nature, Mc graw-hill, 1995.

[6] G.-G. Lee, "Visual Preference in Green Roof Sites", Journal of the Korean Institute of Landscape Architecture, vol.34, no. 5, Sep. 2006, pp.32-38.

[7] S.-E. Yoon, An Introduction to Floral Design, Kimondang, Seoul, 2007.

[8] J.-H. Suh, O.-K. Kim, and H.-S. Yeo, "A Study on the Analysis of Visual Preference and Image for the Display Type of Outdoor Floral Sculpture". Journal of the Korean Society People Plants Environment, vol. 11, no. 3, Sep. 2008, pp.11-26.

[9] O.-K. Kim, A Study of the Outdoor Floral Sculptures for the Improvement of the Urban Landscape, doctoral dissertation, Kyung-Hee University, 2008.

[10] S.-k. Back, A study on the Design Checklist for Ecologically Sustainable Public Space, doctoral dissertation, Hong- Ik University, 2009.

[11] I.-H. Bae, Study on An-yang city residents' preference in cityscape and image, doctoral dissertation, Sung-KyunKwan University, 2009.

[12] Y.-J. Suh, Study on the Visual Preference of Streetscape Considering the Cognition Characteristics Structure, master's dissertation, Han-Yang University, 2009.

[13] M.-J. Jang, A Study on the Living Street Design Methods According to Residents' Satisfaction, master's dissertation, Seoul City University, 2009.

[14] S.-H. Ju, Study on the Selection and the Application of Landscape Adjectives for the Urban Landscape Analysis, doctoral dissertation, Seoul National University, 2003.

[15] J.-K. Kim, and S.-H. Oh, "Psychological Evaluation of Streetscape and Physical Components of Streetscape", Journal of the Korean Society of Civil Engineers, vol, 21. No.1, Feb. 2001, pp. 23-31.

[16] S.-B. Im, Theories in Landscape Analysis, Seoul National University Press, Seoul, 1991.

[17] E.-J. Oh, Study on Demonstration of Floral and Plant Design in the Indoor Public Space, master's dissertation, Dan-Kook University, Korea, 2010.

[18] T. Nisijawa, The Outdoor Environmental Design:Street Furniture, Kimondang, Seoul, 1991.

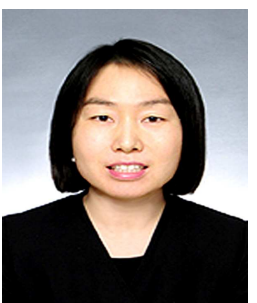

\section{Sung-Eun Yoon}

She received the B.S. in environmental design from Ewha womans university, the M.S in design management from Ewha womans university, Korea in 2001, 2007 respectively. She is currently a professor in the department of floral design at Chungkang College of cultural industries. Her main research interests include floral design and design for green city.

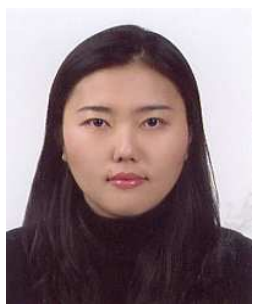

\section{Kyung-Eun Cha}

She received the B.S. in product design from Ewha womans university, the M.S in design management from Ewha womans university, Korea in 2000, 2007 respectively. Her main research interests include design research and design marketing.

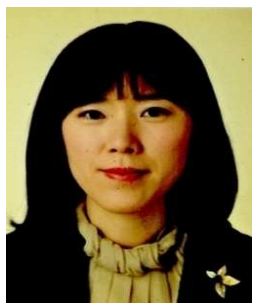

\section{Eu-Jean Jang}

She received the B.S., M.S., and Ph,D in the department of horticultural science from Korea university, Korea in 2002, 2004 and 2010 years respectively. Her main research interests include horticultural therapy.

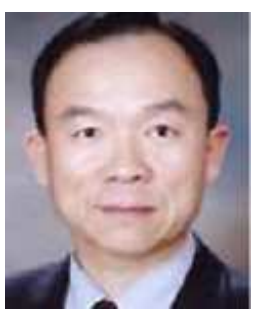

\section{Chun-Ho Park}

He received the B.S., M.S., and $\mathrm{Ph}, \mathrm{D}$ in the department of horticultural science from Korea university, Korea. $\mathrm{He}$ is currently a professor in the college of life sciences \& biotechnology at Korea University. 